\title{
ANALISIS UPAYA PENINGKATAN HUBUNGAN SOSIAL ANTAR TEMAN SEBAYA MELALUI LAYANAN BIMBINGAN KELOMPOK DI SMPN 26 SURABAYA
}

\author{
Aisijah Hartati \\ SMP Negeri 26 Surabaya \\ hartati.smp26@gmail.com
}

\begin{abstract}
Abstrak
Remaja sangat ingin diterima dan dipandang sebagai anggota kelompok teman sebaya, baik di sekolah maupun di luar sekolah, oleh karenanya mereka cenderung bertingkah laku seperti kelompok teman sebayanya. Berdasarkan kenyataan di lapangan yang diperoleh dari hasil wawancara dengan guru pembimbing dan observasi awal dapat diperoleh informasi bahwa di SMP Negeri 26 Surabaya terdapat siswa-siswa yang dapat menjalin hubungan sosial dengan baik dan ada siswa yang kurang dapat menjalin hubungan sosial dengan baik. Penelitian ini termasuk penelitian dengan desain pre-eksperiment yaitu penelitian ini belum memenuhi persyaratan seperti cara eksperimen yang dikatakan ilmiah mengikuti peraturan-peraturan tertentu. Populasi penelitian ini adalah siswa kelas VIII SMP Negeri 26 Surabaya dan dengan teknik sampel purposive diambil 38 siswa yaitu kelas VIII A SMP Negeri 26 Surabaya yang memiliki kemampuan hubungan sosial rendah namun hal ini tidak menjadi suatu permasalahan yang fatal sehingga dapat ditangani menggunakan layanan bimbingan kelompok. Tingkat hubungan sosial antar teman sebaya siswa sebelum mendapatkan layanan bimbingan kelompok (treatment) tergolong dalam kategori tinggi atau baik. Tingkat hubungan sosial antar teman sebaya siswa setelah mendapat layanan bimbingan kelompok tergolong dalam kategori sangat tinggi atau sangat baik. Berdasarkan uji wilcoxon bahwa kondisi apost test terdapat peningkatan hubungan sosial antar teman sebaya setelah diberikan layanan bimbingan kelompok. Sehingga hubungan sosial antar teman sebaya dapat ditingkatkan melalui layanan bimbingan kelompok
\end{abstract}

Kata Kunci: Hubungan Sosial, Teman Sebaya, Layanan Bimbingan Kelompok

\begin{abstract}
Teenagers want to be accepted and seen as members of peer groups, both at school and outside of school, so they tend to behave like peer groups. Based on the facts in the field obtained from the results of interviews with the supervisor and initial observations, information can be obtained that in SMP Negeri 26 Surabaya there are students who can establish social relations well and there are students who lack social relations properly. This research is a research with a pre-experiment design, that is, this research has not fulfilled the requirements such as the way of experimentation which is said to be scientific following certain regulations. The population of this study was eighth-grade students of SMP Negeri 26 Surabaya and with a purposive sample technique 38 students were taken, namely eighth grade class A-SMP Negeri 26 Surabaya who had low social relations skills, but this did not become a fatal problem so that it could be handled using group guidance services. The level of social relations between students' peers before getting group guidance services is classified as high or good. The level of social relations between students' peers after receiving group guidance services is classified as very high or very good. Based on the Wilcoxon test that a post test conditions there is an increase in social relationships between peers after being given group guidance services. So that social relationships between peers can be improved through group guidance services.
\end{abstract}

Keywords: Social Relations, Peers, Group Counseling Services

\section{PENDAHULUAN}

Manusia terlibat dalam situasi sosial, dimana terdapat hubungan antara manusia yang satu dengan manusia yang lain yang dapat saling mempengaruhi. Hubungan sosial dimulai dari tingkat yang sederhana yang didasari oleh kebutuhan yang sederhana. Semakin dewasa, kebutuhan manusia menjadi kompleks, dan dengan demikian tingkat hubungan sosial juga berkembang menjadi sangat kompleks.Perkembangan awal perilaku eksternalisasi remaja dipengaruhi oleh perilaku eksternalisasi temanteman mereka (Veenstra et al., 2013 ).

Remaja sebagai makhluk sosial yang membutuhkan kehadiran orang lain, dibutuhkan adanya keselarasan diantara manusia itu sendiri. Agar interaksi berjalan dengan baik remaja diharapkan untuk dapat berfikir, bersikap, dan bertingkah laku yang sesuai atau cocok dengan tuntutan lingkungannya serta eksistensinya sebagai seorang remaja. Harapan dan tuntutan tersebut diistilahkan dengan tugas perkembangan remaja. Menurut Hurlock (1997: 9) menyatakan bahwa pengertian tugas 
perkembangan adalah tugas yang muncul pada saat atau sekitar periode tertentu dari kehidupan manusia, individu yang jika berhasil akan menimbulkan fase bahagia dan membawa kearah keberhasilan dalam melaksanakan tugas-tugas berikutnya. Akan tetapi kalau gagal menimbulkan rasa tidak bahagia dan kesulitan dalam menghadapi tugas-tugas perkembangan berikutnya. Periode ini terjadi perubahan besar dan esensial mengenai kematangan fisik dan psikis yang berpengaruh terhadap perkembangan berfikir, bahasa, emosi dan sosial remaja.

Remaja sebagai manusia yang sedang tumbuh dan berkembang terus melakukan interaksi sosial baik antara remaja maupun terhadap lingkungan lain. Salah satu tugas dari perkembangan masa remaja yang tersulit adalah hubungan dengan penyesuaian sosial (Hurlock, 1997: 213), remaja harus menyesuaiakan diri dengan lawan jenis dalam hubungan yang sebelumnya belum pernah ada dan harus menyesuaiakan dengan orang dewasa diluar lingkungan keluarga dan sekolah. Menurut Alisyahbana dalam Ali dan Asroi (2005: 85) hubungan sosial diartikan sebagai cara-cara individu bereaksi terhadap orang-orang disekitarnya dan bagaimana pengaruh hubungan itu terhadap dirinya, termasuk juga penyesuaian diri terhadap lingkungan seperti makan dan minum sendiri, berpakaian sendiri, bagaimana mentaati peraturan-peraturan dan perjanjian-perjanjian dalam kelompok atau organisasi, dan sebagainya.

Menurut Hurlock (1997:13) untuk mencapai tujuan dari pola sosialisasi dewasa, remaja harus banyak membuat penyesuaian baru yang terpenting dan tersulit adalah penyesuaian diri dengan meningkatnya pengaruh kelompok teman sebaya, perubahan dalam perilaku sosial, pengelompokan sosial yang baru, nilai-nilai baru dalam seleksi pemimpin. Kelompok teman sebaya memegang peranan penting dalam kehidupan remaja. Remaja sangat ingin diterima dan dipandang sebagai anggota kelompok teman sebaya, baik di sekolah maupun di luar sekolah, beberapa penelitian sebelumnya telah menyarankan kontrol diri yang dikaitkan dengan kemungkinan yang penyesuaian perilaku berdasarkan teman sebaya (Gardner et al.2008 ; Wright et al. 2001 )

Berdasarkan kenyataan di lapangan yang diperoleh dari hasil wawancara dengan guru pembimbing dan observasi awal dapat diperoleh informasi bahwa di SMP Negeri 26 Surabaya terdapat siswa-siswa yang dapat menjalin hubungan sosial dengan baik dan ada siswa yang kurang dapat menjalin hubungan sosial dengan baik, gejala yang muncul antara lain siswa kurang dapat menunjukan komunikasi antar pribadi yang baik, sehingga menyebabkan komunikasi yang kurang efektif, baik komunikasi verbal maupun non verbal, misalnya mudah cemas, mudah gugup, ketika berkomunikasi tidak memperhatikan kontak mata dengan lawan komunikasi, lebih pendiam, selain itu siswa yang kurang dapat menjalin hubungan sosial dengan baik mengalami kesulitan untuk menyesuaikan diri dengan teman dan lingkungan sekitarnya, sehingga menyebabkan kurangnya kerjasama siswa dilingkungan sekolah.

Kesulitan yang dialami siswa dalam menjalin hubungan sosial dengan teman sebayanya dapat menimbulkan masalah dalam mengembangkan potensi yang dimilikinya sehingga dapat mempengaruhi prestasinya disekolah. Hal tersebut didukung oleh hasil peneltian bahwa siswa yang berada di fase remaja awal tidak hanya memilih teman yang mirip dengan mereka dalam perilaku tetapi mereka juga beradaptasi perilaku mereka menjadi lebih mirip dengan teman-teman mereka (Burk et al. 2012 ; Huisman dan Bruggeman 2012). Melihat masa remaja yang sangat potensial dan dapat berkembang kearah positif maupun negatif maka intervensi edukatif dalam bentuk pendidikan, bimbingan maupun pendampingan sangat diperlukan untuk mengarah perkembangan potensi remaja tersebut agar berkembang ke arah positif dan produktif.

Layanan bimbingan dan konseling di sekolah bertujuan untuk membantu individu mengembangkan diri secara optimal sesuai dengan tahap perkembangan dan predisposisi yang dimiliknya (seperti kemampuan dasar dan bakat-bakatnya), berbagai latar belakang yang ada serta sesuai dengan tuntutan positif linkungannya. Menurut Prayitno (1995: 2) menyatakan bahwa layanan bimbingan kelompok merupakan salah satu layanan bimbingan dan konseling yang bertujuan untuk mengembangkan kemampuan sosialisasi siswa, khususnya kemampuan komunikasi peserta layanan yang di berikan oleh konselor sekolah untuk membantu individu menjadi insan yang berguna dalam kehidupannya yang memiliki berbagai wawasan, pandangan, interpretasi, pilihan, penyesuaian dan ketrampilan yang tepat berkenaan dengan diri sendiri dan linkungannya.

Kemampuan bersosialisai/ berkomunikasi seseorang sering terganggu oleh perasaan, pikiran, persepsi, wawasan dan sikap yang tidak obyektif, sempit, dan terkungkung serta tidak efektif, maka dengan adanya kegiatan bimbingan kelompok diharapkan mampu memberikan bantuan kepada individu agar dapat mengatur kegiatan-kegiatan hidup, mengembangkan sudut pandangnya, mengambil keputusannya sendiri dan menanggung bebannya sendiri serta dapat mengembangkan perkembangan sosial secara maksimal. Layanan bimbingan kelompok dijadikan pilihan layanan untuk meningkatkan hubungan sosial siswa terhadap teman sebaya karena layanan bimbingan kelompok merupakan proses pemberian bantuan dalam situasi kelompok dari konselor kepada klien dengan memanfaatkan dinamika kelompok untuk mencapai 
tujuan yaitu perubahan pada diri klien baik itu dalam bentuk pandangan, sikap, sifat, maupun keterampilan yang lebih memungkinkan siswa untuk mewujudkan diri secara lebih optimal dengan tetap memperhatikan potensi yang dimilikinya.

Pada pelaksanaan bimbingan kelompok, dinamika kelompok sengaja ditumbuh kembangkan karena dinamika kelompok adalah hubungan interpersonal yang ditandai dengan semangat kerjasama antar anggota kelompok, saling berbagi pengetahuan, pengalaman dan mencapai tujuan kelompok, sehingga melalui dinamika kelompok kemampuan berkomunikasi, dan bersosialisasi dengan teman sebaya dapat ditingkatkan.

\section{METODE}

Jenis penelitian dalam penelitian ini adalah penelitian eksperimen. Menurut Arikunto penelitian eksperimen (2006: 3) adalah suatu cara untuk mencari hubungan sebab akibat (hubungan kausal) antara dua faktor yang sengaja ditimbulkan oleh peneliti dengan mengurangi atau menyisihkan faktor-faktor lain yang bisa mengganggu. Eksperimen selalu dilakukan dengan maksud untuk melihat suatu perlakuan.

Secara garis besar eksperimen dibagi menjadi dua desain yaitu pre-eksperimental dan true-eksperimental design. Adapun desain yang digunakan dalam penelitian ini adalah pre-eksperimental desain yang disebut juga dengan "quasi eksperiment" atau "eksperimen pura-pura". Alasan penelitian ini termasuk penelitian dengan desain pre-eksperiment yaitu penelitian ini belum memenuhi persyaratan seperti cara eksperimen yang dikatakan ilmiah mengikuti peraturan-peraturan tertentu.

Adapun langkah-langkah yang akan ditempuh dalam pelaksanaan eksperimen penelitian ini meliputi:

\section{a. Pre Test}

Pre test dilakukan dengan menggunakan instrument berupa skala Psikologi hubungan sosial. Adapun tujuan Pre Test dalam penelitian ini adalah untuk mengetahui hubungan sosial pada siswa sebelum diberi layanan bimbingan kelompok.

\section{b. Treatment/ perlakuan}

Perlakuan (treatment) yang diberikan adalah berupa bimbingan kelompok. Tujuan tretment dalam penelitian ini adalah untuk meningkatkan hubungan sosial antar teman sebaya. Adapun frekuensi dan lamanya pertemuan tergantung pada penerimaan dan kesanggupan anggota kelompok. Rencananya treatment akan diberikan sebanyak 8 kali dengan durasi waktu 40 menit untuk setiap kali pertemuan.
Tabel 1. Rancangan Topik Tugas Bimbingan Kelompok

\begin{tabular}{|c|c|c|c|c|}
\hline $\begin{array}{l}\text { No } \\
\text {. }\end{array}$ & $\begin{array}{l}\text { Pert } \\
\text { emu } \\
\text { an }\end{array}$ & $\begin{array}{l}\text { Indikator } \\
\text { kreativitas } \\
\text { yang akan } \\
\text { dikembang } \\
\text { akan }\end{array}$ & Topik Tugas & Waktu \\
\hline 1. & I & $\begin{array}{l}\text { Memiliki } \\
\text { sahabat } \\
\text { dekat }\end{array}$ & $\begin{array}{l}\text { Persahabatan } \\
\text { a. Pengertian sahabat } \\
\text { b.Faktor-faktor penghancur } \\
\text { hubungan persahabatan } \\
\text { c. Cara-cara menjaga } \\
\text { keharmonisan hubungan } \\
\text { persahabatan }\end{array}$ & $\begin{array}{l}40 \\
\text { menit }\end{array}$ \\
\hline 2. & II & $\begin{array}{l}\text { Keterampil } \\
\text { an sosial }\end{array}$ & $\begin{array}{l}\text { Cara-cara bergaul yang } \\
\text { baik } \\
\text { a. Faktor-fator penyebab } \\
\text { perselisihan } \\
\text { b. Dampak negatif } \\
\text { perselisihan } \\
\text { c. Cara-cara menjalin } \\
\text { hubungan baik } \\
\text { d. Dampak positif } \\
\text { hubungan baik antar teman } \\
\text { sebaya }\end{array}$ & $\begin{array}{l}40 \\
\text { menit }\end{array}$ \\
\hline 3 & III & $\begin{array}{l}\text { Interaksi } \\
\text { Sosial }\end{array}$ & $\begin{array}{l}\text { Kerjasama Kelompok } \\
\text { a. Bentuk-bentuk } \\
\text { kerjasama kelompok } \\
\text { b. Hal-hal yang harus } \\
\text { dilakukan ketika } \\
\text { bekerjasama } \\
\text { c. Tujuan dan manfaat } \\
\text { kerjasama }\end{array}$ & $\begin{array}{l}40 \\
\text { menit }\end{array}$ \\
\hline 4 & IV & $\begin{array}{l}\text { Keterampil } \\
\text { an Sosial }\end{array}$ & $\begin{array}{l}\text { Mengatasi konflik antar } \\
\text { pribadi } \\
\text { a. Contoh-contoh konflik } \\
\text { b. Dampak terjadinya } \\
\text { konflik } \\
\text { c. Cara mengatasi } \\
\text { konflik }\end{array}$ & $\begin{array}{l}40 \\
\text { menit }\end{array}$ \\
\hline 5 & $\mathrm{~V}$ & $\begin{array}{l}\text { Penyesuaia } \\
\text { n Sosial }\end{array}$ & $\begin{array}{l}\text { Penyesuaian diri } \\
\text { a. Pengertian penyesuaian } \\
\text { diri } \\
\text { b. Dampak positif } \\
\text { penyesuaian diri yang baik } \\
\text { c. Cara-cara } \\
\text { mengembangkan } \\
\text { kemampuan penyesuaian } \\
\text { diri yang baik } \\
\end{array}$ & $\begin{array}{l}40 \\
\text { menit }\end{array}$ \\
\hline 6 & VI & $\begin{array}{l}\text { Dipercaya } \\
\text { oleh teman } \\
\text { sebaya } \\
\text { dalam } \\
\text { posisi } \\
\text { tanggung } \\
\text { jawab } \\
\text { tertentu }\end{array}$ & $\begin{array}{l}\text { Menjadi pribadi yang baik } \\
\text { dan bertanggung jawab } \\
\text { a. Pengertian pribadi yang } \\
\text { baik dan bertanggung } \\
\text { jawab } \\
\text { b. Faktor-faktor penyebab } \\
\text { sulitnya bertanggung } \\
\text { jawab } \\
\text { c. Langkah-langkah } \\
\text { menjadi pribadi yang baik } \\
\text { dan bertanggung } \\
\text { jawab }\end{array}$ & $\begin{array}{l}40 \\
\text { menit }\end{array}$ \\
\hline 7 & VII & $\begin{array}{l}\text { Interaksi } \\
\text { Sosial }\end{array}$ & $\begin{array}{l}\text { Befikir positif } \\
\text { a. Pengertian berfikir } \\
\text { positif } \\
\text { b. Ciri-ciri berfikir positif } \\
\text { c. Manfaat berfikir } \\
\text { positif }\end{array}$ & $\begin{array}{l}40 \\
\text { menit }\end{array}$ \\
\hline 8 & VIII & $\begin{array}{l}\text { Interaksi } \\
\text { Sosial }\end{array}$ & $\begin{array}{l}\text { Perbedaan kelompok atau } \\
\text { genk } \\
\text { a. Pengertian perbedaan } \\
\text { kelompok atau genk } \\
\text { b. Dampak adanya genk } \\
\text { c. Cara-cara menghindari } \\
\text { terjadinya dampak negatif } \\
\text { dari genk }\end{array}$ & $\begin{array}{l}40 \\
\text { menit }\end{array}$ \\
\hline
\end{tabular}




\section{c. Post Test}

Post test adalah hasil perlakuan dengan menggunakan skala psikologi hubungan sosial kepada sampel penelitian sesudah diberi perlakuan. Kemudian untuk mengetahui efektif tidaknya bimbingan kelompok melalui post test, yaitu membandingkan skala psikologi hubungan sosial antar teman sebaya pada Pre Test dan Post test dari anggota yang mendapatkan perlakuan.

\section{d. Proses Analisis Data}

Proses analisis data yaitu menganalisis data yang sudah terkumpul dengan menggunakan perhitungan $u j i$ wilcoxon. Alasan menggunakan analisis uji wilcoxon karena data dalam penelitian bentuknya ordinal atau berjenjang (Sugiyono, 2007: 45).

\section{Populasi dan Sampel}

Populasi penelitian ini adalah siswa kelas VIII SMP Negeri 26 Surabaya, dengan rombongan belajar 10 kelas tiap kelasnya 38 siswa, jadi populasi kelas VIII berjumlah 380 siswa.

Pada penelitian ini teknik sampling yang digunakan adalah sampling purposive atau sampel bertujuan. Sampling purposive adalah teknik penentuan sampel dengan pertimbangan tertentu (Arikunto, 2006). Kriteria purposifnya adalah kelas yang memiliki kemampuan hubungan sosial rendah namun hal ini tidak menjadi suatu permasalahan yang fatal sehingga dapat ditangani menggunakan layanan bimbingan kelompok, sehingga pada penelitian terpilih kelas VIII A SMP Negeri 26 Surabaya dengan pengambilan sampel beku/keseluruhan berjumlah 38 siswa.

\section{HASIL DAN PEMBAHASAN}

Berdasarkan pada tujuan dan hasil dari penelitian yang telah dilakukan, maka akan dibahas secara rinci tentang gambaran hubungan sosial antar teman sebaya melalui layanan bimbingan kelompok pada siswa kelas VIII A SMP Negeri 26 Surabaya. Dalam menjalin hubungan sosial sebelum diberi layanan atau treatment, maupun sesudah diberikan treatment tentang gambaran hubungan sosial antar teman siswa kelas VIII A SMP Negeri 26 Surabaya juga dalam evaluasi melalu pre test dan pos test pada siswa yang berjumlah 38 siswa. Kelas VIII A SMP Negeri 26 Surabaya tidak ditemukan siswa yang sangat tidak sesuai (STS) atau sangat rendah sekali dalam melaksanakan hubungan sosialnya antar teman di sekolah $(0,00 \%)$ siswa, demikian juga dalam katagori hubungan sosial antar teman yang tidak sesuai (TS) atau hubungan sosial yang rendah di sekolah $(0,00 \%)$ siawa. Pada kegiatan yang lain baik pada waktu pre test maupun pos test.
Sedang siswa yang hubungan sosial antar teman yang katagori sedang atau cukup sebelum mendapatkan treatment sebesar $(57,89 \%)$ siswa dan menunjukkan penurunan sesudah mendapatkan treatment sebesar $(15,78 \%)$ siswa. Pada tingkat tinggi atau baik hubungan sosial antar teman sebelum mendapatkan treatmen yakni $(31,57 \%)$ dan pada siswa yang sesudah mendapatkan treatment hubungan sosialnya naik menjadi $(55,26 \%)$ siswa. Dan pada hubungan sosial antar teman menjadi sangat tinggi (ST) pada waktu sebelum diberi treatment mencapai $(10,52 \%)$ siswa naik dengan pesat sesudah diberi treatment menjadi $(28,94 \%)$ siswa. Untuk kegiatan pre test tentang hubungan sosial antar teman mencapai nilai 3.005, dengan rata-rata 79,08 dan prosentase ketuntasan 71,06\% (belum tuntas), namun sesuadah diberi treatment tentang hubungan sosial antar teman di sekolah nilainya menjadi 3.282 , dengan rata-rata 86,37 dan prosentase ketuntasan mencapai $86,85 \%$ (tuntas).

Keterampilan sosial yang baik dalam penelitian ini seperti yang di ungkapkan oleh Smitson dan Alport (dalam Hartati, 2004: 13) keterampilan sosial yaitu kemampuan untuk menjalin hubungan dengan orang lain dengan cukup yaitu dengan cukup lancar, mampu memimpin dan mengorganisir serta mampu mengatasi perselisihan yang muncul dalam setiap kegiatan. Keterampilan-keterampilan ini menurut Desmita (2009: 230) antara lain: (1) berkomunikasi, (2) memecahkan masalah, (3) mengelola perasaan dan implus-implus, (4) mengukur temperamen sendiri dan orang lain, (5) menjalin hubungan-hubungan yang saling mempercayai. Sedangkan menurut Buhmester (dalam Sulistiana: 2010) menyatakan bahwa aspek-aspek ketrampilan sosial dapat dijabarkan sebagai berikut: (1) kemampuan berinisiatif, (2) kemampuan berempati, (3) kemampuan bersikap terbuka, (4) kemampuan bersifat asertif, (5) kemampuan memberikan dukungan emosional, (6) kemampuan mengatasi konflik.

Berdasarkan Hasil analisis deskriptif persentase kondisi awal sebelum mendapatkan perlakuan berupa layanan bimbingan kelompok indikator memiliki keterampilan sosial yang baik termasuk dalam kategori rendah. Hal ini juga dapat dilihat dari hasil pengamatan selama proses layanan kegiatan bimbingan kelompok yaitu pada pertemuan pertama siswa belum dapat berkomunikasi secara lancar, kemampuan ber inisiatif untuk mengungkapkan pendapatnya juga belum terlihat baik. Siswa masih malu-malu dan ragu untuk mengungkapkan pendapatnya. Kemampuan untuk bersikap terbuka dan berempati terhadap pendapat orang.

Hasil penelitian ini menunjukkan bahwa pengendalian diri yang baik pribadi dari hubungan sosial antar teman sebaya menjadi kekuatan penting dalam pengembangan perilaku yang terkontrol (Franken et al., 2016) Temuan 
kami juga menyarankan kontrol diri sebagai faktor dasar dan penting dalam perkembangan remaja (Moffitt et al. 2011). Meskipun menjakin hubungan interpersonal dengan orang lain merupakan kebutuhan dasar, dalam arti mendasari bagi pemenuhan kebutuhan-kebutuhan hidup yang lain, faktanya tak setiap individu manusia - karena beberapa alasan - tak memiliki kesanggupan untuk membangun hubungan interpersonal dengan orang lain (Darminto dan Hariastuti, 2019)

\section{PENUTUP}

Tingkat hubungan sosial antar teman sebaya siswa sebelum mendapatkan layanan bimbingan kelompok (treatment) tergolong dalam kategori tinggi atau baik. Tingkat hubungan sosial antar teman sebaya siswa setelah mendapat layanan bimbingan kelompok tergolong dalam kategori sangat tinggi atau sangat baik. Berdasarkan uji wilcoxon bahwa kondisi akhir/ post test terdapat peningkatan hubungan sosial antar teman sebaya setelah diberikan layanan bimbingan kelompok. Sehingga hubungan sosial antar teman sebaya dapat ditingkatkan melalui layanan bimbingan kelompok

Berdasar hasil penelitian diketahui bahwa hubungan sosial antar teman sebaya siswa kelas VIII A SMP Negeri 26 Surabaya tahun Pelajaran 2018-2019 dapat ditingkatkan melalui layanan bimbingan kelompok, berkenaan hal tersebut implementasi kedepannya diharapkan bagi guru pembimbing hendaknya memiliki inisiatif dan dapat menentukan waktu yang tepat untuk pelaksanaan kegiatan bimbingan kelompok sehingga kegiatan bimbingan kelompok dapat terlaksana secara teratur dan baik.

\section{DAFTAR PUSTAKA}

Ali dan Asrori. 2005. Psikologi Remaja Perkembangan Peserta Didik. Jakarta: PT Bumi Aksara.

Arikunto, Suharsimi. 2006. Prosedur Penelitian Suatu Pendekatan Prakteik. Jakarta: Rineka Cipta.

Burk, W. J., van der Vorst, H., Kerr, M., \& Stattin, H. 2012. Alcohol use and friendship dynamics: Selection and socialization in early-, middle-, and late-adolescent peer networks. Journal of Studies on Alcohol and Drugs, 73, 89-98.

Darminto, Eko; dan Retno Tri Hariastuti. 2019. Penggunaan Konseling Berpasangan Untuk Membantu Peserta Didik Menangani Hambatan Interpersonal. Jurnal Bikotetik, 3 (2), 40-85.

Desmita. 2009. Psikologi Perkembangan. Bandung: PT Remaja Rosdakarya

Franken, Aart; Terrie E. Moffitt; Christian E. G. Steglich; Jan Kornelis Dijkstra; Zeena Harakeh; Wilma A. M. Vollebergh. 2016. The Role of Self-Control and Early Adolescents' Friendships in the Development of Externalizing Behavior: The SNARE Study.
Journal Youth Adolescence. 45, 1800-1811. DOI 10.1007/s10964-015-0287-z

Gardner, T. W., Dishion, T. J., \& Connell, A. M. 2008. Adolescent self-regulation as resilience: Resistance to antisocial behavior within the deviant peer context. Journal of Abnormal Child Psychology, 36, 273-284. doi:10.1007/s10802-007-9176-6

Hartati, S. 2004. Pembelajaran Kecerdasan Emosi Melalui Bimbingan Konseling Kelompok. Semarang: Konvensi Nasional ABKIN

Huisman, C., \& Bruggeman, J. 2012. The social network, socioeconomic background, and school type of adolescent smokers. International Journal of Behavioral Development, 36, 329-337. doi:10.1177/0165025412444078

Hurlock, Elizabeth B. 1997. Psikologi Perkembangan Suatu Pendekatan Sepanjang Rentan Kehidupan. Jakarta: Erlangga

Moffitt, T. E., \& Caspi, A. 2001. Childhood predictors differentiate life-course persistent and adolescencelimited antisocial pathways among males and females. Development and Psychopathology, 13, 355-375. doi:10.1017/S0954579401002097

Prayitno. 1995. Layanan Bimbingan dan Konseling Kelompok (Dasar dan Profil). Jakarta: Ghalia Indonesia.

Sugiyono. 2005. Statistika Untuk Penelitian. Bandung: CV Alvabeta.

Veenstra, R., Dijkstra, J. K., Steglich, C., \& van Zalk, M. H. W. 2013. Network-behavior dynamics. Journal of Research on Adolescence, 23, 399-412. doi:10.1111/jora.12070

Wright, B. R. E., Caspi, A., Moffitt, T. E., \& Silva, P. A. 2001. The effects of social ties on crime vary by criminal propensity: A life-course model of interdependence. Criminology, 39, 321-352. doi:10.1111/j.1745-9125.2001.tb00925.x 